\title{
Transcriptome changes induced by docetaxel in human mammary cell lines expressing different levels of ERBB2
}

\author{
M.L. DOS SANTOS ${ }^{1}$, K.P. GIMENES ${ }^{1}$, W.A. SILVA Jr ${ }^{2}$ and M.A. NAGAI ${ }^{1}$ \\ ${ }^{1}$ Disciplina de Oncologia, Departamento de Radiologia da Faculdade de Medicina da Universidade de São Paulo, \\ Av. Dr. Arnaldo 455, $4^{\circ}$ andar, sala 4112, 01246-903, São Paulo; ${ }^{2}$ Departamento de Genética, \\ Faculdade de Medicina de Ribeirão Preto - USP, Ribeirão Preto, Brazil
}

Received November 14, 2008; Accepted January 12, 2009

DOI: 10.3892/ijmm_00000187

\begin{abstract}
The taxane docetaxel is currently the most effective chemotherapeutic drug for the treatment of advanced breast cancer. However, a considerable proportion of breast cancer patients do not respond positively to docetaxel. The mechanisms of docetaxel resistance are poorly understood. Overexpression of ERBB2 occurs in 15-30\% of breast tumors and is associated with chemoresistance to a variety of anticancer drugs. In the present study, we sought to identify genes involved in ERBB2-mediated chemoresistance to docetaxel. We generated SAGE libraries from two human mammary cell lines expressing basal (HB4a) and high (C5.2) levels of $E R B B 2$ before and after intensive exposure to docetaxel and identified potential ERBB2 target genes implicated in a variety of cellular processes including cell proliferation, cell adhesion, apoptosis and cytoskeleton organization. Comparison of the transcriptome of the cell lines before and after docetaxel exposure revealed substantially different expression patterns. Twenty-one differentially expressed genes between HB4a and C5.2 cell lines, before and after docetaxel treatment, were further analyzed by qPCR. The alterations in the expression patterns in HB4a and C5.2 cell lines in response to docetaxel treatment observed by SAGE analysis were confirmed by qPCR for the majority of the genes analyzed. Our study provides a comprehensive view of the expression changes induced in two human mammary cells expressing different levels of $E R B B 2$ in response to docetaxel that could contribute to the elucidation of the mechanisms involved in ERBB2-mediated chemoresistance in breast cancer.
\end{abstract}

Correspondence to: Dr Maria Aparecida Nagai, Disciplina de Oncologia, Departamento de Radiologia da Faculdade de Medicina da Universidade de São Paulo, Av. Dr. Arnaldo, 455, $4^{\circ}$ andar, CEP 01246-903, São Paulo, Brazil

E-mail: nagai@usp.br

Key words: breast cancer, docetaxel, ERBB2, drug resistance, chemotherapy, SAGE

\section{Introduction}

Breast cancer is the most commonly diagnosed malignancy and the second leading cause of mortality related to cancer in women living in Western countries (1). In spite of the advances in our knowledge of the numerous genetic and epigenetic changes associated with human breast carcinogenesis, chemotherapy is still the choice for patients with advanced breast tumors. A major clinical problem associated with fatality of advanced breast cancer patients is the intrinsic or acquired resistance to chemotherapy that leads to a high recurrence rate and reduced overall survival (2). To date, there are no clinically useful predictive markers to distinguish patients who are likely to respond effectively to a chemotherapeutic regimen.

The taxanes paclitaxel and docetaxel are anti-microtubule agents that exert their anti-proliferative effects by binding to the $\beta$ subunit of tubulin, a key component of microtubules, dynamic polymers that play various roles in cell physiology, including cell division (3). Taxane binding prevents microtubule depolymerization (4), which disrupts normal mitotic spindle formation resulting in an inhibition of cell division at the G2-M phase of the cell cycle $(5,6)$.

Docetaxel is currently the most effective chemotherapeutic drug for the treatment of advanced breast cancer (7). However, a considerable proportion of breast cancer patients do not respond positively to docetaxel, but instead suffer from side effects. To date, the mechanisms of docetaxel resistance are poorly understood. Intrinsic or acquired docetaxel resistance has been associated with altered expression of several genes: 1) overexpression of P-glycoprotein $(8,9) ; 2)$ altered expression of B-tubulin isotypes (10); 3) reduced expression of p27 (11); 4) overexpression of CYP3A4 (12); 5) overexpression of the BRCA2 gene (13); 6) overexpression of CCT5, RGS3 and YKT6 genes (14); 7) amplification of 7q21 and loss of 10q chromosome region (9); and 8) overexpression of ERBB2 $(15,16)$. However, the clinical significance of these proposed predictive factors remains to be established.

Overexpression of ERBB2, a member of the transmembrane receptor tyrosine kinase family, occurs in $15-30 \%$ of invasive breast tumors $(17,18)$ and is associated with increased aggressiveness and chemoresistance to a variety of anticancer drugs, including docetaxel $(15,16,19)$. ERBB2 is 
proving to be an excellent target for therapeutic approaches in breast cancer. Indeed, the recombinant humanized monoclonal anti-ERBB2 antibody, Herceptin, has been shown to have significant therapeutic effects in patients with ERBB2positive breast cancer, particularly when combined with anticancer drugs such as paclitaxel and docetaxel (20).

Investigation of docetaxel modulated gene expression may lead to the identification of biomarkers of docetaxel clinical activity, which may be useful in overcoming resistance. In the present study, we sought to identify genes involved in ERBB2-mediated chemoresistance to docetaxel, and examined differential gene expression from SAGE libraries of two human mammary luminal cell lines expressing different levels of ERBB2 before and after intensive exposure to docetaxel.

\section{Materials and methods}

Cell culture and treatment. The mammary cell lines, HB4a and C5.2, were kindly provided by Dr Michael O'Hare from the Ludwig Institute for Cancer Research, London, UK. The C5.2 cell line was established by transfection of parental normal mammary luminal epithelial HB4a cells with fulllength normal human ERBB2 cDNA derived from the breast cancer cell line BT474 (21). Cells were cultured in RPMI1640 supplemented with $10 \%$ fetal calf serum (FCS), 2 mM glutamine, $100 \mathrm{IU} / \mathrm{ml}$ penicillin, $100 \mu \mathrm{g} / \mathrm{ml}$ streptomycin and $5 \mu \mathrm{g} / \mathrm{ml}$ hydrocortisone and insulin in a $5 \% \mathrm{CO}_{2}$ humidifier incubator at $37^{\circ} \mathrm{C}$. The breast carcinoma cell line, SKBR3, was kindly provided by Dr Anamaria Aranha Camargo (Ludwig Institute for Cancer Research, São Paulo, Brazil). SKBR3 cells were cultured in RPMI-1640 supplemented with $10 \%$ fetal calf serum (FCS), $2 \mathrm{mM}$ glutamine, $100 \mathrm{IU} / \mathrm{ml}$ penicillin, $100 \mu \mathrm{g} / \mathrm{ml}$ streptomycin in a $5 \% \mathrm{CO}_{2}$ humidifier incubator at $37^{\circ} \mathrm{C}$. Docetaxel (Taxotere) was obtained from Aventis Pharmaceuticals Inc., Bridgewater, NJ and diluted in ethanol at $10^{-2} \mathrm{M}$ and stored at $-20^{\circ} \mathrm{C}$. The cells were made resistant to docetaxel by short-term in vitro exposure to $5 \mathrm{nM}$ docetaxel for $1 \mathrm{~h}$ followed by treatment with increasing concentrations of docetaxel (0.01-1 $\mu \mathrm{M}$ for C5.2 cells and $0.01-0.250 \mu \mathrm{M}$ for HB4a cell line) each $24 \mathrm{~h}$.

RNA extraction. After the treatments, the cells were washed twice with PBS and harvested. Total RNA was extracted from cultured cells by the guanidine isothiocyanate method as previously described (22). The quality of the RNA samples was determined by $1 \%$ agarose gel electrophoresis and ethidium bromide staining. All RNA samples were treated with DNaseI for $1 \mathrm{~h}$ at $37^{\circ} \mathrm{C}$ to eliminate genomic DNA contamination.

Serial analysis of gene expression (SAGE). Total RNA (25 $\mu \mathrm{g})$ isolated from HB4a and C5.2 cell lines before and after intensive exposure to docetaxel were used to generate SAGE libraries. SAGE was carried out using the I-SAGE kit (Invitrogen, Carlsbad, CA) according to the manufacturer's protocol based on the original SAGE method (23). Tag frequency tables were obtained from sequences by SAGE ${ }^{\mathrm{TM}}$ analysis software, with minimum tag count set to one, maximum ditag length set to 28 , and other parameters set as default. The annotation was based on SAGEmap (http://www.
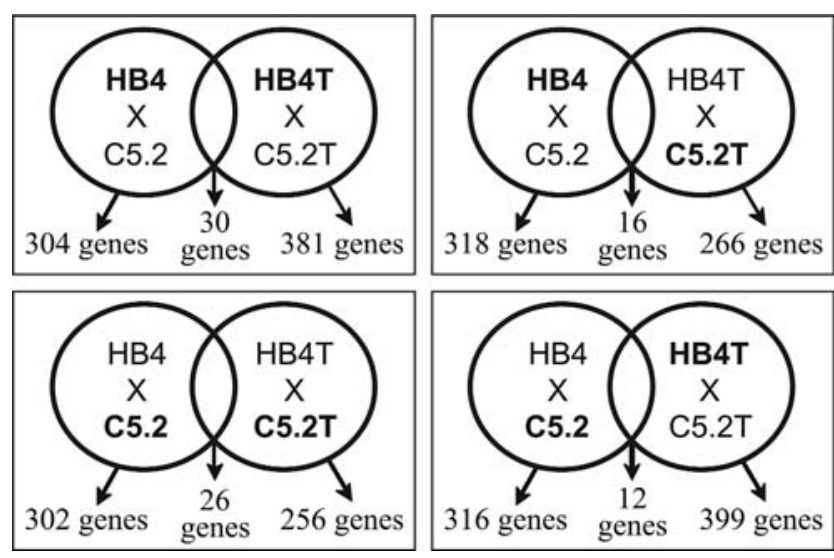

Figure 1. Venn diagrams of the number of differentially expressed genes in SAGE libraries generated from HB4a and C5.2 cell lines before and after intensive exposure to docetaxel. Using a cutoff of $\geq 4$ fold changes we identified 411 genes more expressed in HB4a and 282 genes more expressed in C5.2 cells after treatment with docetaxel.

ncbi.nlm.nih.gov/SAGE) and CGAP SAGE Genie (http://cgap. ncbi.nih.gov/SAGE). Statistical analysis was carried out with the H2G (hyper- and hypo-expressed genes) software (http://www.gdm.fmrp.usp.br/h2g) for the comparison of two SAGE libraries. H2G was also used to perform the normalization of compared libraries using the library with the highest number of tags as reference. Functional categorization of the differentially expressed genes was performed using GO (www.geneontology.org). Network analysis of the SAGE data was performed using the Ingenuity pathway analysis software (Ingenuity Systems Inc.).

Transfection of cells with siRNA. C5.2 cells were cultured in 6-well plates with complete medium until they reach $50 \%$ confluence. Medium was then replaced by medium without serum and antibiotics and cells were transfected with $50 \mathrm{nM}$ of siERBB2 or siControl (siC) in RPMI-1640 using Lipofectamine reagent (Invitrogen) and OptiMEM (Invitrogen) according to the manufacturer's instructions. After 6 h, 10\% FCS, insulin and hydrocortisone were added to the cultures. siRNA transfected cells were grown in complete medium for $72 \mathrm{~h}$, and cells were then harvested for total RNA and protein extraction.

Western blotting. Untransfected, siControl (siC) and ERBB2 siRNA (siERBB2) transfected C5.2 cells were washed 3 times with PBS, harvested by scraping and collected in PBS. The cell suspension was centrifuged at 2,000 rpm for $2 \mathrm{~min}$. The pellet was dissolved in lysis buffer ( $50 \mathrm{mM} \mathrm{Na}$ pyrophosphate, $50 \mathrm{mM} \mathrm{NaF}, 5 \mathrm{mM} \mathrm{NaCl}, 5 \mathrm{mM}$ PMSF, $100 \mathrm{mM} \mathrm{Na}_{3} \mathrm{VO}_{4}$ ) and centrifuged at $13,000 \mathrm{rpm}$ for $15 \mathrm{~min}$ at $4^{\circ} \mathrm{C}$. The supernatant was collected and stored at $-70^{\circ} \mathrm{C}$. Protein concentration was measured using Bradford reagent (Pierce, Rockford, IL). Aliquots (15 $\mu \mathrm{g}$ of protein) from each sample were separated by electrophoresis on a 7.5\% SDS-polyacrylamide gel and transferred to a nitrocellulose membrane at $100 \mathrm{~V}$ for $2 \mathrm{~h}$ using transfer buffer (24 mM Tris, $193 \mathrm{mM}$ glycine, 20\% methanol). The membranes were blocked in 5\% non-fat dried milk in TBS containing $0.1 \%$ Tween-20 (TBSt) for $1 \mathrm{~h}$ at room temperature and then incubated overnight in a cold room with $3 \%$ albumin containing anti-ERBB2 antibody. Blots were washed 3 times 

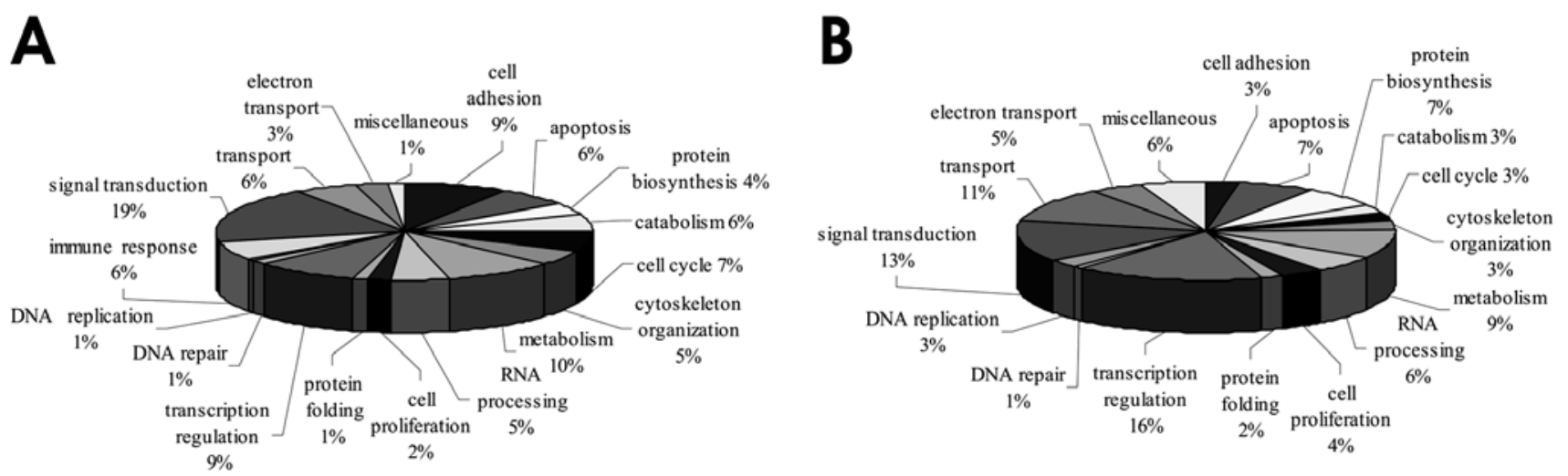

Figure 2. Distribution of the highly expressed transcripts from HB4a (A) and C5.2 (B) cell lines after docetaxel treatment after classification into functional categories using Gene Ontology nomenclature.

with TBSt and incubated with anti-ß-actin antibody for $1 \mathrm{~h}$ After three washes in TBSt for 10 min blots were incubated with peroxidase-conjugated anti-mouse secondary antibody (all antibodies were purchased from Chemicon International, Billerica, MA and diluted 1:1000). Following three washes, labeled proteins were detected using Supersignal West Pico (Pierce).

Quantitative real-time PCR ( $q P C R)$. Total RNA $(10 \mu \mathrm{g})$ was reverse transcribed using the High capacity cDNA archive kit (Applied Biosystems). PCR amplification was performed using an Applied Biosystems PRISM 5700 sequence detector and the Platinum SYBR Green qPCR SuperMix-UDG kit (Invitrogen) following the manufacturer's recommendations. qPCR reactions were carried out under the following conditions: $50^{\circ} \mathrm{C}$ for $2 \mathrm{~min}, 95^{\circ} \mathrm{C}$ for $10 \mathrm{~min}$ followed by 40 cycles at $95^{\circ} \mathrm{C}$ for $15 \mathrm{sec}$ and $55^{\circ} \mathrm{C}$ for $1 \mathrm{~min}$. Gene expression was normalized against GAPDH expression as an internal control. The results were expressed as $n$-fold differences in gene expression relative to the calibrator sample. The relative expression was calculated by $2^{-\Delta \Delta C T}(C T=$ fluorescence threshold value; $\Delta \mathrm{CT}=\mathrm{CT}$ of the target gene $-\mathrm{CT}$ of the reference gene $(\mathrm{GAPDH}) ; \Delta \triangle \mathrm{CT}=\Delta \mathrm{CT}$ of the target sample - $\triangle \mathrm{CT}$ of the reference sample).

\section{Results}

The aim of this study was to identify potential candidate genes involved in docetaxel resistance mediated by ERBB2 amplification and/or overexpression. We employed SAGE technique to examine the gene expression profile from two normal mammary cell lines, HB4a and C5.2, which express different levels of ERBB2 before and after intensive exposure to docetaxel.

A total of 307,506 tags was generated by sequencing from HB4a (81,684 tags; 30,854 unique tags), HB4a treated with docetaxel (70,715; 31,546 unique tags), C5.2 (79,948 tags; 30,568 unique tags) and C5.2 treated with docetaxel $(75,159$; 31,293 unique tags). Analysis of the expression profiles of HB4a and C5.2 cells prior to docetaxel treatment was previously published (24).

Comparison of the transcriptome of the cell lines prior to and after docetaxel exposure revealed substantially different expression patterns. Alterations in expression patterns of the top 50 previously identified genes as more expressed in HB4a and C5.2 cells (24) in response to docetaxel treatment are shown in Tables I and II. Using a cutoff of $\geq 4$-fold changes in examining the differences in expression between the transcripts from HB4a and C5.2 libraries, we detected increased expression of 411 distinct genes in HB4a and 282 distinct genes in $\mathrm{C} 5.2$ treated with docetaxel. Among the genes differentially expressed between HB4a and C5.2 treated with docetaxel, only a few genes were also found to be differentially expressed prior to treatment (see Venn diagrams in Fig. 1). A considerably higher number of ESTs and hypothetical proteins were identified in the cell line C5.2, which express high levels of ERBB2, after docetaxel exposure. Functional characterization of the genes differentially expressed between HB4a and C5.2 cell lines prior to docetaxel treatment was previously reported (24).

HB4a cells exposed to intense docetaxel treatment showed higher percentage of genes involved in apoptosis (HB4a+Doc, $6 \%$ vs. HB4a-Doc, $1 \%$ ), cell adhesion (HB4a+Doc 9\% vs. HB4a-Doc, 2\%) and immune response (HB4a+Doc, 6\% vs. HB4a-Doc, 2\%) compared to HB4a cells before docetaxel treatment (Fig. 2). The genes differentially expressed between HB4a and C5.2 cell lines were also subjected to Ingenuity pathway analysis (www.ingenuity.com). Analysis of the genes down- and up-regulated in the cell lines before and after docetaxel treatment confirmed that ERBB2 is a key molecule associated with the modulation of gene expression in our system (Figs. 3 and 4).

Based on tag abundance and functional annotation, 21 of the differentially expressed genes in the HB4a and C5.2 cells before and after intensive exposure to docetaxel were selected for validation by qPCR. This panel included 14 up-regulated genes (MATR3, ATAD4, HDGF, CENPH, LGALS1, AES, ANP32B, LEMD3, CAV1, BTG1, COQ10B, DBNDD2, NDRG1 and C6orf115) and 7 down-regulated genes (ACTN1, ETFB, RUVBL1, DUSP1, SPARC, TPM1 and SFRP1) in C5.2 compared to HB4a cells, before intensive exposure to docetaxel. This first validation was performed using the cDNA samples previously used for the construction of the SAGE libraries. The alterations in the expression patterns between HB4a and C5.2 cell lines in response to docetaxel treatment as assessed by qPCR were consistent with the 
Table I. Gene expression changes of the top 50 genes down-regulated in C5.2 versus HB4a mammary cells in response to docetaxel treatment.

\begin{tabular}{|c|c|c|c|c|c|c|}
\hline TAG & UniGene & Description (locus name) & $\mathrm{HB} 4 \mathrm{a}^{\mathrm{a}}$ & $\mathrm{C} 5.2^{\mathrm{a}}$ & HB4T & C5.2T \\
\hline AAAATATTTT & Hs.509765 & Actinin, $\alpha 1$ (ACTN1) & 23 & 1 & 11 & 11 \\
\hline AAAGCCAAGA & Hs. 654553 & Electron-transfer-flavoprotein, $B$ polypeptide (ETFB) & 18 & 0 & 19 & 2 \\
\hline AAGTGAGATG & Hs. 272822 & RuvB-like 1 (E.coli) (RUVBL1) & 15 & 0 & 2 & 1 \\
\hline AAGAGTTACG & Hs. 55041 & Mitochondrial ribosomal protein L2 (MRPL2) & 15 & 1 & 5 & 3 \\
\hline AGAAATGTAT & Hs. 282113 & SNF1-like kinase (SNF1LK) & 14 & 1 & 11 & 5 \\
\hline AGTGTGATAC & Hs. 118820 & Hypothetical protein $\mathrm{BC} 007882$ (LOC152217) & 14 & 1 & 3 & 7 \\
\hline AGGAAAAGAT & Hs. 523829 & Polymerase (DNA-directed), $\delta 4$ (POLD4) & 12 & 1 & 15 & 3 \\
\hline CTTGACATAC & Hs.171695 & Dual specificity phosphatase 1 (DUSP1) & 12 & 1 & 13 & 4 \\
\hline AGGGCTACGG & BF571807 & EST & 12 & 1 & 2 & 0 \\
\hline CCAGCCCAGC & Hs.29802 & Slit homolog 2 (Drosophila) (SLIT2) & 11 & 1 & 4 & 3 \\
\hline ACTGCGAGGA & Hs. 110477 & Dolichyl-phosphate mannosyltransferase polypeptide 3 (DPM3) & 10 & 0 & 1 & 7 \\
\hline ATGTCTTTTC & Hs.462998 & Insulin-like growth factor binding protein 4 (IGFBP4) & 10 & 1 & 7 & 5 \\
\hline GGCCTTTTTT & Hs.75307 & $\mathrm{H} 1$ histone family, member $\mathrm{X}$ (H1FX) & 10 & 1 & 3 & 3 \\
\hline CTACGTGCTC & Hs.521056 & $\begin{array}{l}\text { ATP synthase, } \mathrm{H}^{+} \text {transporting, mitochondrial F0 complex, } \\
\text { subunit } \mathrm{f} \text {, isoform } 2 \text { (ATP5J2) }\end{array}$ & 9 & 1 & 1 & 0 \\
\hline AATTTGCAAC & Hs. 420272 & H2A histone family, member Y (H2AFY) & 9 & 1 & 6 & 2 \\
\hline CTTGATTCCC & Hs. 518374 & Quiescin Q6 sulfhydryl oxidase 1 (QSOX1) & 9 & 1 & 5 & 6 \\
\hline CACTTGAAAA & Hs. 7753 & Calumenin (CALU) & 9 & 1 & 6 & 1 \\
\hline TTGGGAGCAG & Hs. 445403 & Isoleucine-tRNA synthetase (IARS) & 9 & 1 & 7 & 3 \\
\hline ACGATTGATG & Hs. 528320 & Apolipoprotein A-I binding protein (APOA1BP) & 9 & 1 & 3 & 4 \\
\hline AAAATAAAAA & Hs. 517373 & Protoporphyrinogen oxidase (PPOX) & 9 & 1 & 2 & 6 \\
\hline CGTTCCTGCG & Hs.504609 & $\begin{array}{l}\text { Inhibitor of DNA binding 1, dominant negative } \\
\text { helix-loop-helix protein (ID1) }\end{array}$ & 9 & 1 & 3 & 1 \\
\hline ATGTGAAGAG & Hs.111779 & Secreted protein, acidic, cysteine-rich (osteonectin) (SPARC) & 141 & 17 & 22 & 18 \\
\hline GATCCCAAAC & BF686592 & EST & 8 & 0 & 5 & 3 \\
\hline TTCTTGCTTA & Hs. 425777 & Ubiquitin-conjugating enzyme E2L 6 (UBE2L6) & 8 & 0 & 20 & 2 \\
\hline AAGAAAACTG & Hs. 561815 & Staufen, RNA binding protein, homolog 2 (Drosophila) (STAU2) & 8 & 0 & 3 & 2 \\
\hline CTTGGTTCTC & Hs. 501578 & Mitochondrial GTPase 1 homolog (S. cerevisiae) (MTG1) & 8 & 0 & 1 & 0 \\
\hline AATACCTCGT & Hs.414579 & Scotin (SCOTIN) & 8 & 0 & 11 & 3 \\
\hline GTTGCTGCCC & Hs.9234 & Transmembrane protein 147 (TMEM147) & 8 & 0 & 3 & 0 \\
\hline TTAAAGATTT & Hs. 133892 & Tropomyosin $1(\alpha)($ TPM1) & 8 & 0 & 4 & 4 \\
\hline GCCAAGATGC & Hs. 515164 & $\begin{array}{l}\text { Growth arrest and DNA-damage-inducible, } \gamma \text { interacting protein } 1 \\
\text { (GADD45GIP1) }\end{array}$ & 16 & 2 & 4 & 5 \\
\hline AACATTCTAA & Hs.530436 & Syntaxin binding protein 3 (STXBP3) & 8 & 1 & 4 & 4 \\
\hline TATCAATATT & Hs. 213424 & Secreted frizzled-related protein 1 (SFRP1) & 8 & 1 & 0 & 1 \\
\hline AAGGAGTCCC & Hs. 558499 & CD320 molecule (CD320) & 8 & 1 & 1 & 2 \\
\hline CTCTAGAACC & Hs.292579 & Phosphatidylserine synthase 1 (PTDSS1) & 8 & 1 & 2 & 3 \\
\hline GCATCTGTTT & Hs.520189 & $\begin{array}{l}\text { ELOVL family member } 5 \text {, elongation of long chain fatty acids } \\
\text { (ELOVL5) }\end{array}$ & 8 & 1 & 2 & 2 \\
\hline AACCAGAGGT & Hs. 529280 & Anaphase promoting complex subunit 7 (ANAPC7) & 8 & 1 & 4 & 2 \\
\hline TAACAAAGAA & Hs.632540 & $\begin{array}{l}\text { Protein kinase, interferon-inducible double-stranded } \\
\text { RNA dependent activator (PRKRA) }\end{array}$ & 8 & 1 & 1 & 10 \\
\hline GAATAAAATA & Hs. 269592 & Coiled-coil and $\mathrm{C} 2$ domain containing $1 \mathrm{~A}(\mathrm{CC} 2 \mathrm{D} 1 \mathrm{~A})$ & 8 & 1 & 8 & 5 \\
\hline GACTCTTCAG & Hs. 534293 & $\begin{array}{l}\text { Serine (or cysteine) proteinase inhibitor, clade A } \\
\text { ( } \alpha-1 \text { antiproteinase, antitrypsin), member } 3 \text { (SERPINA3) }\end{array}$ & 8 & 1 & 0 & 10 \\
\hline TGATTTATTC & Hs. 465870 & Kelch-like ECH-associated protein 1 (KEAP1) & 8 & 1 & 5 & 3 \\
\hline ATGGCAACAG & Hs.505654 & Integrin, $\alpha 5$ (fibronectin receptor, $\alpha$ polypeptide) (ITGA5) & 8 & 1 & 5 & 2 \\
\hline TGGCTTAAAT & Hs. 433213 & Hypoxia-inducible protein 2 (HIG2) & 8 & 1 & 0 & 0 \\
\hline AAAGTGCATC & Hs.193326 & Fibroblast growth factor receptor-like 1 (FGFRL1) & 8 & 1 & 4 & 2 \\
\hline GACCTCCTGC & Hs. 502872 & Mitogen-activated protein kinase kinase kinase 11 (MAP3K11) & 8 & 1 & 2 & 1 \\
\hline GATTTCAACC & Hs.371698 & RNA export 1 homolog (S. pombe) (RAE1) & 7 & 0 & 1 & 2 \\
\hline GTGGGGGGAG & Hs. 446374 & Prefoldin subunit 6 (PFDN6) & 7 & 0 & 4 & 4 \\
\hline AATGACTGAA & Hs.93659 & Protein disulfide isomerase family A, member 4 (PDIA4) & 7 & 0 & 4 & 4 \\
\hline ATGCGGGAGA & Hs. 534521 & Transmembrane protein 54 (TMEM54) & 7 & 0 & 2 & 0 \\
\hline CACTCTATCC & Hs. 258551 & Aspartyl aminopeptidase (DNPEP) & 7 & 0 & 2 & 0 \\
\hline TACAAACCTG & Hs. 513626 & Metallothionein $1 \mathrm{~F}$ (functional) (MT1F) & 7 & 0 & 4 & 1 \\
\hline
\end{tabular}

T, treated wih docetaxel. ados Santos et al (24). 
Table II. Gene expression changes of the top 50 genes up-regulated in C5.2 versus HB4a mammary cells in response to docetaxel treatment.

\begin{tabular}{|c|c|c|c|c|c|c|}
\hline TAG & UniGene & Description (locus name) & $\mathrm{HB} 4 \mathrm{a}^{\mathrm{a}}$ & $\mathrm{C} 5.2^{\mathrm{a}}$ & HB4T & C5.2T \\
\hline CTGTGTTTAG & Hs.268939 & Matrin 3 (MATR3) & 0 & 230 & 0 & 451 \\
\hline CCAGGAACCT & Hs.446352 & $\begin{array}{l}\text { v-erb-b2 erythroblastic leukemia viral oncogene homolog } 2, \\
\text { neuro/glioblastoma derived oncogene homolog (avian) (ERBB2) }\end{array}$ & 0 & 85 & 0 & 44 \\
\hline GCAGGTTCCC & AI624297 & EST & 1 & 19 & 0 & 17 \\
\hline TAAGTAAAGT & Hs. 368260 & ATPase family, AAA domain containing (ATAD4) & 0 & 16 & 0 & 7 \\
\hline CTATTTAGGG & Hs.7736 & Mitochondrial ribosomal protein L27 (MRPL27) & 0 & 16 & 3 & 18 \\
\hline TCTТCТСССТ & Hs. 506748 & $\begin{array}{l}\text { Hepatoma-derived growth factor (high-mobility group } \\
\text { protein 1-like) (HDGF) }\end{array}$ & 1 & 14 & 17 & 6 \\
\hline CCCAGCTAAT & Hs.631967 & Centromere protein $\mathrm{H}(\mathrm{CENPH})$ & 2 & 25 & 4 & 7 \\
\hline TGATTGGTGG & Hs.74615 & $\begin{array}{l}\text { Platelet-derived growth factor receptor, } \alpha \text { polypeptide } \\
\text { (PDGFRA) }\end{array}$ & 1 & 12 & 1 & 7 \\
\hline GCCCCCAATA & Hs.445351 & Lectin, galactoside-binding, soluble, 1 (galectin 1) (LGALS1) & 2 & 23 & 6 & 8 \\
\hline TACCATCGAT & BI226498 & EST & 1 & 11 & 4 & 2 \\
\hline GGCAGAGACC & Hs.574492 & Nucleoporin 62 kDa (NUP62) & 1 & 11 & 3 & 3 \\
\hline GCTCTGCCTC & Hs.252549 & Cathepsin Z (CTSZ) & 0 & 10 & 1 & 1 \\
\hline CACGCAATGC & Hs.515053 & Amino-terminal enhancer of split (AES) & 1 & 10 & 7 & 1 \\
\hline GATTTTGTAG & Hs.494604 & $\begin{array}{l}\text { Acidic (leucine-rich) nuclear phosphoprotein } 32 \text { family, } \\
\text { member B (ANP32B) }\end{array}$ & 2 & 18 & 8 & 8 \\
\hline TAGCTTCCTT & Hs.44276 & Homeo box C10 (HOXC10) & 1 & 9 & 2 & 5 \\
\hline TAAACATTGT & Hs.505905 & LEM domain containing 3 (LEMD3) & 1 & 9 & 1 & 2 \\
\hline GTAGACACCT & Hs.666222 & Ribosomal protein L7 antisense mRNA, partial sequence & 2 & 17 & 0 & 9 \\
\hline ATGGCAGGAG & Hs.617352 & Homo sapiens, clone IMAGE:4715570 & 0 & 8 & 1 & 9 \\
\hline TAAATACAGT & Hs. 503043 & Carnitine palmitoyltransferase 1A (liver) (CPT1A) & 0 & 8 & 4 & 2 \\
\hline TGTATCACTG & BF932124 & EST & 0 & 8 & 0 & 4 \\
\hline CATTGTAATA & BE871060 & EST & 0 & 8 & 1 & 10 \\
\hline CCTAAGGCTA & Hs.108371 & E2F transcription factor 4, p107/p130-binding (E2F4) & 0 & 8 & 4 & 5 \\
\hline TGGATCAACC & Hs.74034 & Caveolin 1, caveolae protein, $22 \mathrm{kDa}(\mathrm{CAV} 1)$ & 0 & 8 & 2 & 0 \\
\hline CAGGAACCTG & Hs. 572315 & Transcribed locus & 0 & 8 & $\mathrm{x}$ & $\mathrm{x}$ \\
\hline TCACAGCTGT & Hs.255935 & B-cell translocation gene 1, anti-proliferative (BTG1) & 2 & 16 & 10 & 9 \\
\hline CTACCAGGCC & Hs.54457 & CD81 molecule (CD81) & 1 & 8 & 3 & 2 \\
\hline TCTCAATTCT & Hs.690198 & Cell division cycle 42 (GTP binding protein, $25 \mathrm{kDa}$ ) (CDC42) & 1 & 8 & 5 & 3 \\
\hline GCTTTCATTG & Hs.708366 & $\begin{array}{l}\text { Nuclear casein kinase and cyclin-dependent kinase substrate } 1 \\
\text { (NUCKS1) }\end{array}$ & 1 & 8 & 2 & 4 \\
\hline TTTTGATAAA & Hs.388927 & YY1 transcription factor (YY1) & 1 & 8 & 7 & 3 \\
\hline TCTGCTAAAG & Hs.593339 & High-mobility group box 1 (HMGB1) & 1 & 8 & 4 & 5 \\
\hline AAGAGTTGGG & AA846582 & EST & 1 & 8 & 0 & 6 \\
\hline TAAGCAGATG & Hs.306425 & Inhibitor of Bruton agammaglobulinemia tyrosine kinase (IBTK) & 1 & 8 & 2 & 1 \\
\hline GCGAAACCCC & Hs.632547 & Coenzyme Q10 homolog B (S. cerevisiae) (COQ10B) & 1 & 8 & 24 & 17 \\
\hline CAGAATAATA & Hs.204475 & HIV TAT specific factor 1 (HTATSF1) & 1 & 8 & 1 & 4 \\
\hline GATTTGTAGC & BE279179 & EST & 2 & 15 & 7 & 7 \\
\hline ACCGCCTGTG & Hs.79625 & Chromosome 20 open reading frame 149 (C20orf149) & 2 & 15 & 8 & 4 \\
\hline TCCTTTGCAA & Hs.81892 & Casein kinase $1, \gamma 1(\mathrm{CSNK} 1 \mathrm{G} 1) 0$ & 7 & 1 & 0 & \\
\hline CTACATAATA & AA903109 & EST & 0 & 7 & 1 & 2 \\
\hline CTGCCTCCTT & Hs. 655055 & $\begin{array}{l}\text { Dysbindin (dystrobrevin binding protein 1) domain containing } 2 \\
\text { (DBNDD2) }\end{array}$ & 0 & 7 & 9 & 12 \\
\hline GCTACAGGTA & Hs.349306 & Ring finger protein 145 (RNF145) & 0 & 7 & 2 & 2 \\
\hline TTCAAGAAAC & Hs.344151 & Golgi autoantigen, golgin subfamily a, 4 (GOLGA4) & 0 & 7 & 1 & 2 \\
\hline CTCATAAGAA & AV722184 & EST & 0 & 7 & 3 & 7 \\
\hline TTAGCTTGTT & BU074305 & EST & 0 & 7 & 1 & 6 \\
\hline CAGGATCCAG & Hs.546303 & $\begin{array}{l}\text { Suppression of tumorigenicity } 13 \text { (colon carcinoma) (Hsp70 } \\
\text { interacting protein) (ST13) }\end{array}$ & 0 & 7 & 1 & 2 \\
\hline GCAGATCGGG & Hs.646417 & $\begin{array}{l}\text { Similar to 60S ribosomal protein L6 (TAX-responsive enhancer } \\
\text { element-binding protein 107) (TAXREB107) (Neoplasm-related } \\
\text { protein C140) (LOC401725) }\end{array}$ & 0 & 7 & 1 & 2 \\
\hline GCGGAGAGAG & BI524265 & EST & 3 & 21 & 8 & 9 \\
\hline AGTAGGTGGC & Hs.591538 & $\begin{array}{l}\text { Transcribed locus, weakly similar to NP_039504.1 } \\
\text { [Schizosaccharomyces pombe] }\end{array}$ & 2 & 14 & 4 & 12 \\
\hline CGAATAAAAT & Hs.139896 & Macrophage erythroblast attacher (MAEA) & 2 & 14 & 4 & 4 \\
\hline TACAATAAAC & Hs.507910 & Progesterone receptor membrane component 2 (PGRMC2) & 1 & 7 & 1 & 7 \\
\hline GTTGTGATGT & Hs.374477 & Ewing sarcoma breakpoint region 1 (EWSR1) & 1 & 7 & 5 & 2 \\
\hline
\end{tabular}

T, treated wih docetaxel. ados Santos et al (24). 


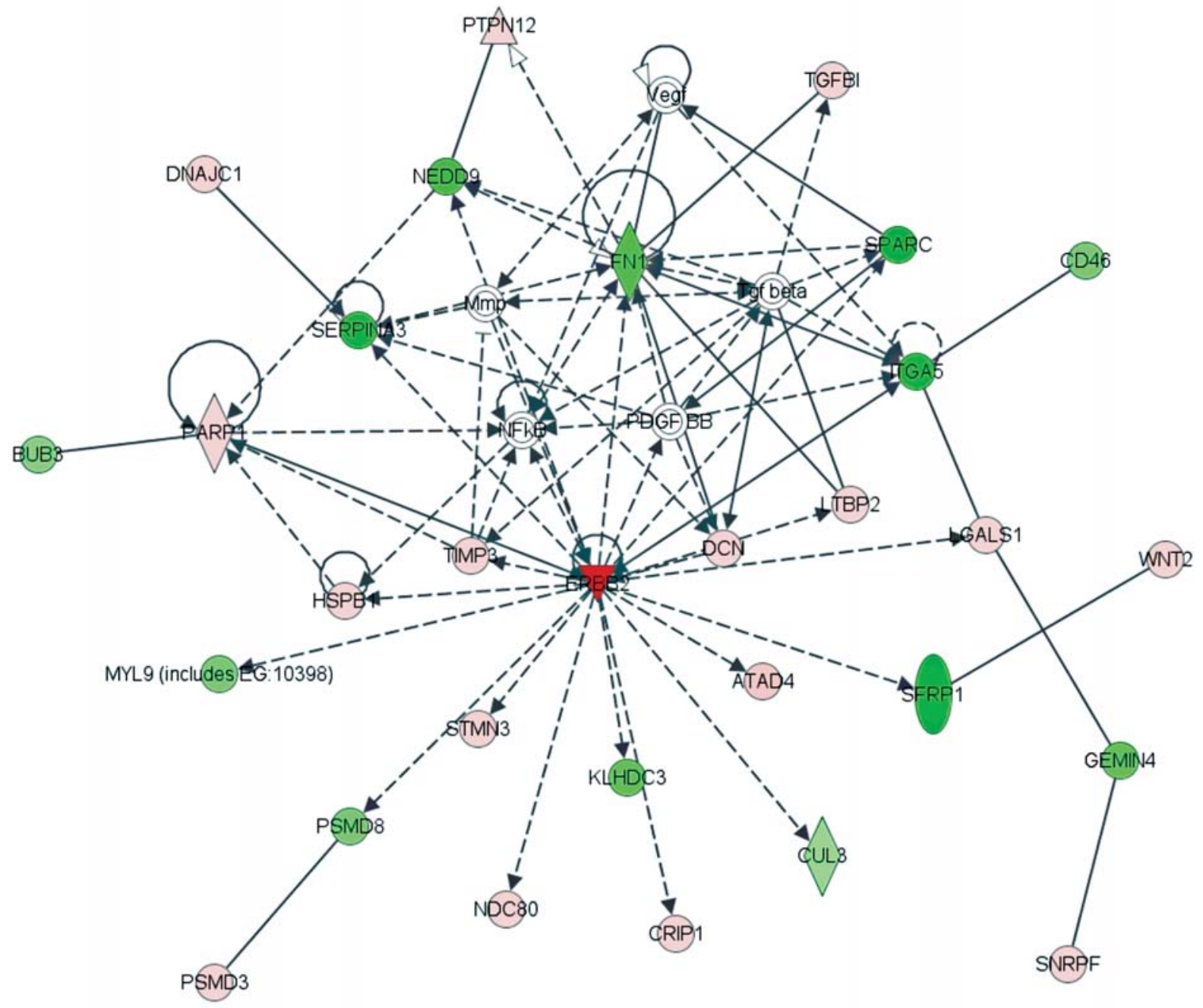

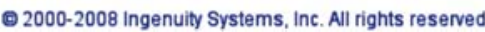

Figure 3. Molecular interaction network showing an integrated view of the up- (red) and down-regulated (green) genes in C5.2 versus HB4a cells. Genes or gene products are represented as nodes, and the biological relationship between two nodes is represented as an edge. The intensity of node color indicates the degree of up- (red) or down- (green) regulation. Edges are displayed with various labels that describe the nature of the relationship between the nodes: — binding only; $\rightarrow$ acts on; curved black arrowhead, auto-regulation. Dotted edges represent an indirect interaction.

results generated by the SAGE method for the majority of genes analyzed. Representative results are shown in Fig. 5 (first two groups of bars).

Additional experiments were performed using cDNA samples from HB4a and C5.2 cells treated with 20 and $100 \mathrm{nM}$ of docetaxel for $24 \mathrm{~h}$. Similar to the representative results shown in Fig. 5 (last groups of bars) for SPARC, RUVBL1, ATAD4 and CENPH, most tested genes exhibited similar down- and up-regulation as observed by SAGE analysis. SAGE and qPCR analysis showed decreased expression of SPARC (secreted protein, acidic, cysteine rich) and RUVBL1 (RuvB-like 1) in C5.2 cells compared to HB4a cells before treatment. Docetaxel treatment of C5.2 cells showed increased expression of SPARC and RUVBL1 leading to a similar expression levels of these genes in both cell lines (Fig. 5, last two groups of bars). In contrast, ATAD4 and CENPH transcripts, which were induced in C5.2 cells compared to HB4a cells prior to treatment showed no modulation (ATAD4) or up-regulation (CENPH) in both cell lines after docetaxel treatment. Therefore, expression levels of ATAD4 and CENPH transcripts were similar before and after docetaxel treatment (Fig. 5).

To further confirm the expression pattern of SPARC, RUVBL1, ATAD4 and CENPH in mammary cell lines expressing different levels of ERBB2, we also examined the expression of these genes in the SKBR3 cell line. The results of three experiments shown in Fig. 6B, confirmed our previous results from SAGE and qPCR analysis, showing a downregulation of SPARC and RUVBL1 transcripts in C5.2 and SKBR3 cells that overexpress ERBB2 compared to HB4a cells and an up-regulation of ATAD4 transcripts in both C5.2 and SKBR3 cells compared to HB4a cells. In contrast to our previous validation experiments, however, CENPH transcripts were shown to be down-regulated in both C5.2 and SKBR3 cell lines compared to HB4a cells. 


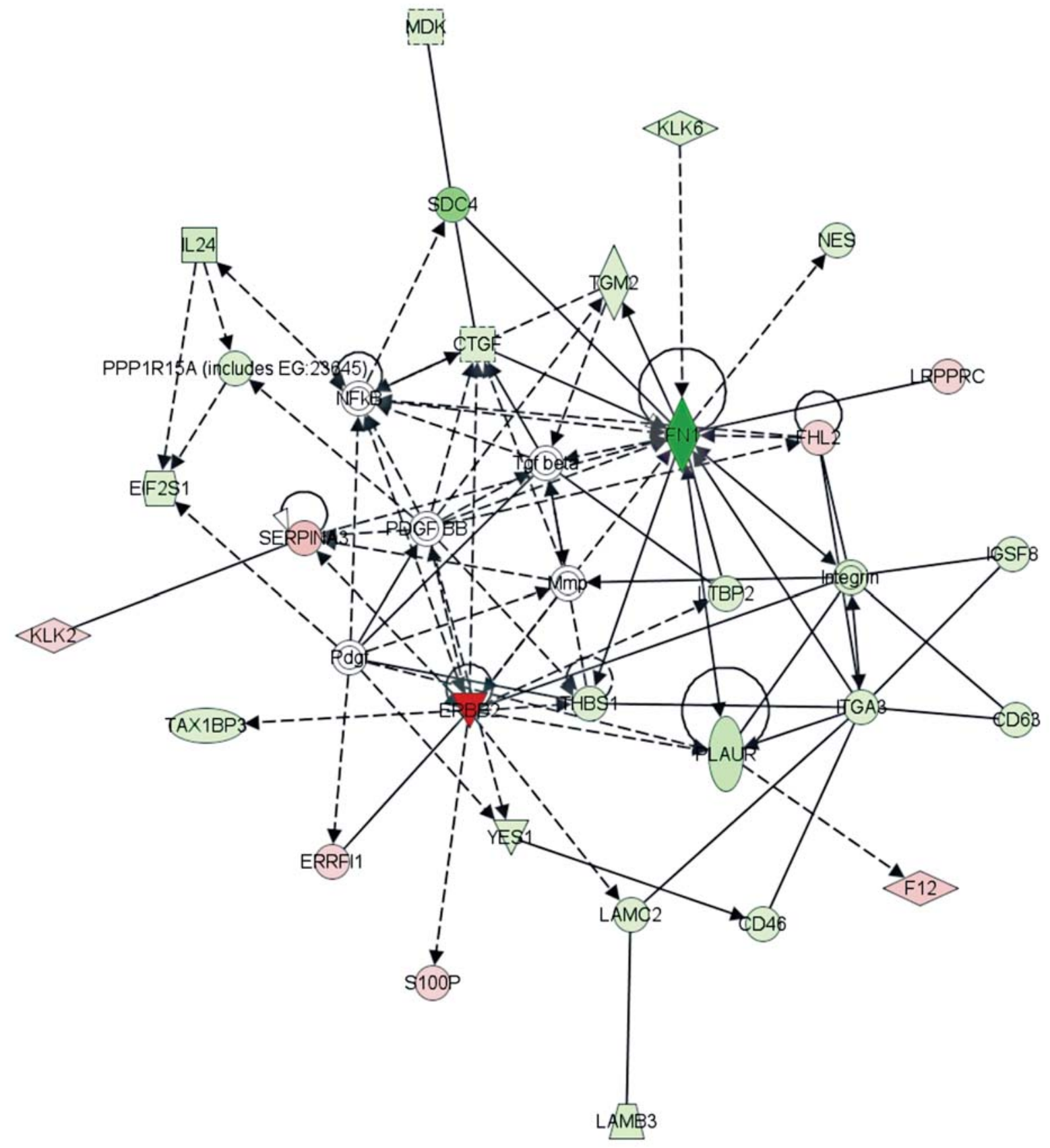

구 2000-2008 Ingenuity Systems, Inc. All rights reserved.

Figure 4. Molecular interaction network showing an integrated view of the up- (red) and down-regulated (green) genes in C5.2 versus HB4a cells after docetaxel treatment. Genes or gene products are represented as nodes, and the biological relationship between two nodes is represented as an edge. The intensity of node color indicates the degree of up- (red) or down- (green) regulation. Edges are displayed with various labels that describe the nature of the relationship between the nodes: — binding only; $\rightarrow$ acts on; curved black arrowhead, auto-regulation. Dotted edges represent an indirect interaction.

We further examined the impact of siRNA-mediated silencing of $E R B B 2$ on the expression of the differentially expressed genes. C5.2 cells transfected with siERBB2 showed a $60-70 \%$ decrease in ERBB2 expression (Fig. 6A). siRNAmediated ERBB2 knockdown leads to decreased expression of ATAD4 found to be up-regulated in C5.2 cells compared to HB4a cells by SAGE and qPCR analysis and increased expression of CENPH transcripts found to be down-regulated in $\mathrm{C} 5.2$ cells compared to HB4a cells by qPCR analysis.
Surprisingly, siERBB2 transfected cells displayed slightly decreased expression of SPARC and RUVBL1 transcripts, which were found by both SAGE and qPCR analysis to be down-regulated in C5.2 cells (Fig. 6B).

\section{Discussion}

Clinical and experimental evidence indicates that amplification and/or overexpression of ERBB2 is associated with docetaxel 

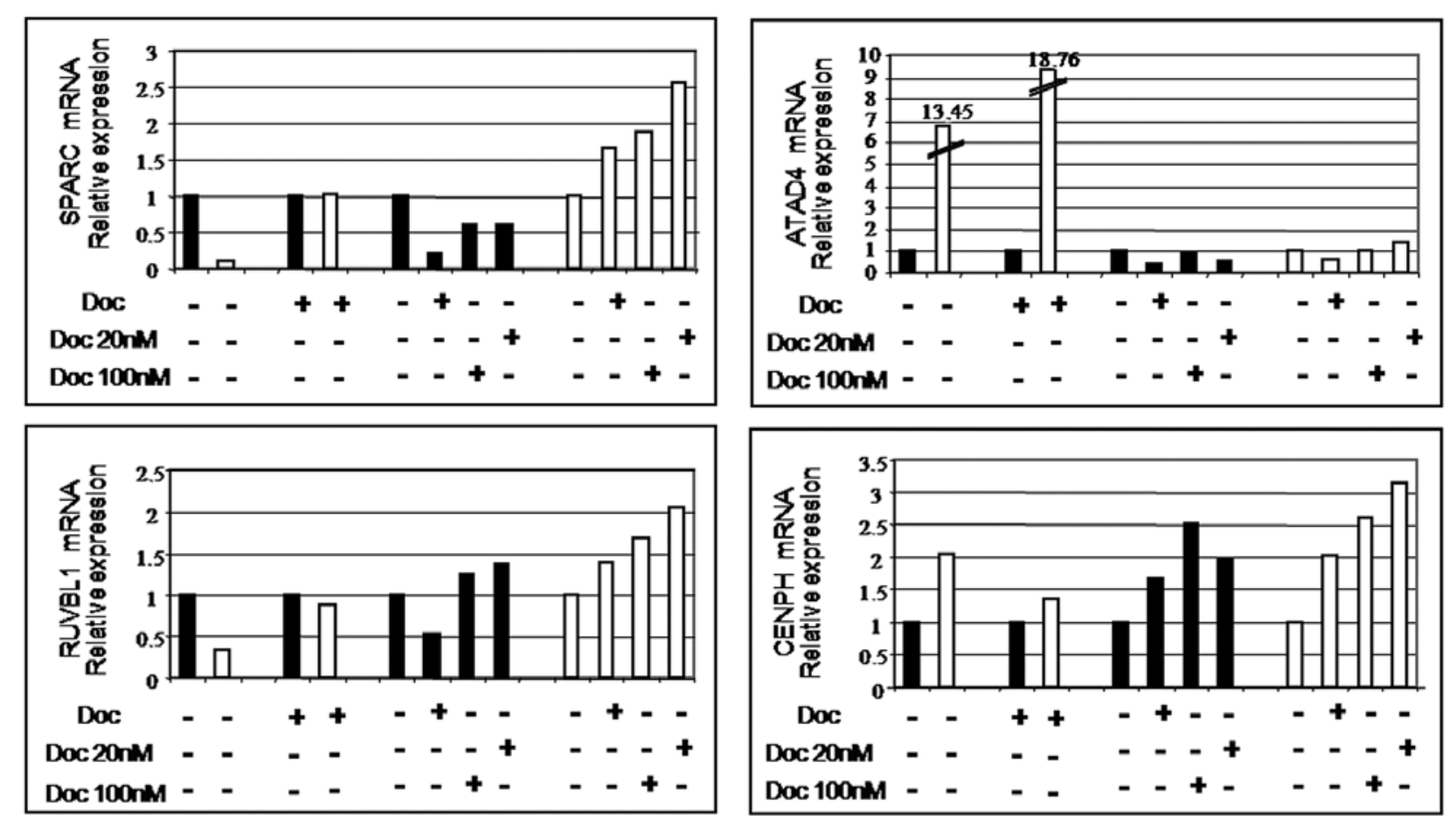

- Hb4a $\quad$ a C5.2

Figure 5. SPARC, RUVBL1, ATAD4, and CENPH expression in Hb4a and C5.2 cell lines before and after docetaxel treatment. The first two groups of bars represent the expression of genes between the HB4a and C5.2 cells before (Doc-) and after intensive exposure to docetaxel (Doc+). The last two groups of bars represent the expression of genes in Hb4a and C5.2 cell lines after treatment with 20 and $100 \mathrm{nM}$ of docetaxel for $24 \mathrm{~h}$.

resistance, but the predictive value of this association is not yet validated or fully understood (19). The aim of our study was to compare the changes in gene expression modulated by docetaxel in two human mammary cell lines expressing different levels of ERBB2 to identify potential candidate genes involved in the molecular mechanism of docetaxel sensitivity and resistance.

Comparative analysis between the mRNA expression profile of docetaxel-treated cells and untreated control cells revealed substantially different expression patterns in response to drug treatment. These differentially expressed genes were subsequently evaluated by their biological function (GO) and molecular interaction network analysis (Ingenuity Pathway Analysis program). In both cell lines, the highly expressed genes are associated with several biological processes. Both before and after docetaxel treatment we observed an overrepresentation of genes associated with signal transduction and cytoskeleton organization in HB4a cells compared to C5.2 cells and an over-representation of genes associated with cell proliferation, apoptosis and transport in C5.2 cells. These differences could be related to drug sensitivity. The most preeminent networks were assembled around the ERBB2 oncogene, indicating that in C5.2 cells ERBB2 is directly or indirectly influencing cell signaling.

Comparison of each cell line before and after intensive exposure to docetaxel reveals some significant changes in gene expression. HB4a cells, shown to be more sensitive to docetaxel, displayed a higher percentage of genes related to cell adhesion, apoptosis and immune response after intensive exposure to docetaxel compared to HB4a cells prior to treatment. Similar to the effects of many other chemo- therapeutic agents, docetaxel exerts its cytotoxic effects by altering cell cycle and apoptosis regulation. Altered expression of genes involved in cell cycle and apoptosis control is observed in docetaxel-resistant human breast cancer cell lines and might be associated with acquired resistance to docetaxel in breast cancer cells (11). Depending on the concentration, docetaxel displays a biphasic cytotoxic effect in breast cancer cells, inducing aberrant mitosis followed by necrosis at a low concentration, and mitotic arrest followed by apoptosis at high concentration; furthermore, these two cytotoxic effects are related with specific gene expression profiles (25).

In addition, several studies have provided evidence that breast cancer cell lines and breast cancer patients exposed to paclitaxel and/or docetaxel show altered expression of several inflammatory cytokines and enzymes that might influence their clinical pharmacology and toxicology (26). Understanding the basis for the over-representation of induced genes related to apoptosis and immune response displayed by HB4a cells in response to docetaxel treatment compared to C5.2 cells that showed over-representation of cell proliferation and apoptosis-related genes and underrepresentation of immune related genes irrespective of docetaxel treatment, could contribute to elucidate the important role of the docetaxel response in breast cancer.

Notably, the intensive exposure to docetaxel resulted in a complex pattern of changes on gene expression profiles. Docetaxel was able to modulate the expression of several genes in both cell lines, indicating that docetaxel sensitivity and resistance involve the integration of many genes and biological pathways. Interesting, many genes, such as SPARC 
A
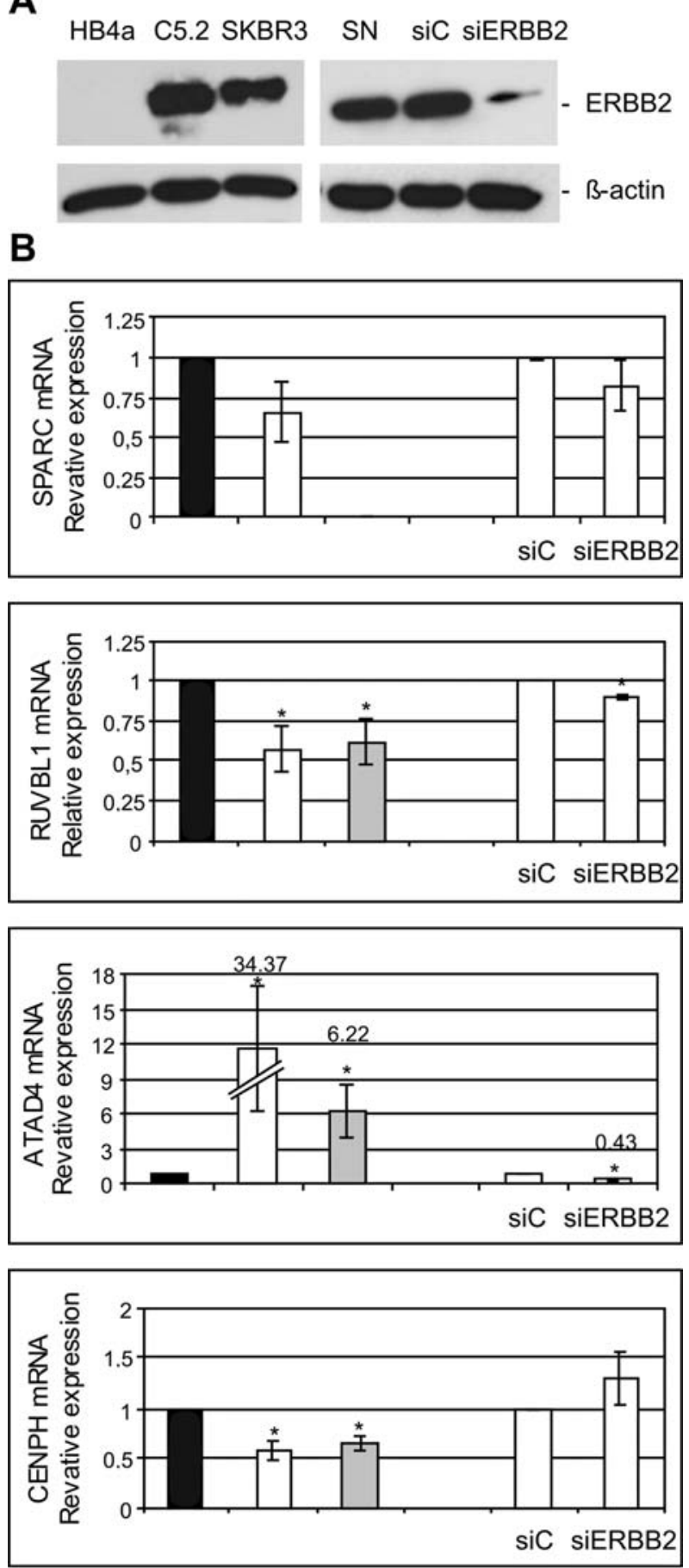

HB4a

C5.2

SKBR3

Figure 6. Effect of siRNA-mediated knockdown of ERBB2 on the expression of SPARC, RUVBL1, ATAD4, and CENPH in the C5.2 cells. (A) Western blotting shows total level of ERBB2 protein in Hb4a, C5.2 and SKBr3, and in C5.2 cells transfected with siControl or with siERBB2. Antibodies against $\beta$-actin were used as an endogenous control. (B) qPCR analysis of relative mRNA expression of SPARC, RUVBL1, ATAD4, and CENPH in $\mathrm{Hb} 4 \mathrm{a}, \mathrm{C} 5.2$ and $\mathrm{SKBr} 3$ cell lines, and in C5.2 cells transfected with siControl or with siERBB2. Results represent mean \pm SD of triplicate experiments. *Student's t-test, values of $\mathrm{p} \leq 0.05$ were considered statistically significant.

and RUVBL1 that were differentially expressed between HB4a and C5.2 cells before drug treatment (24), were up- or down-regulated by docetaxel and showed a very similar expression pattern after docetaxel exposure (data confirmed by qPCR), suggesting that these genes could play an important role in the sensitivity or resistance to docetaxel.

Although the precise molecular mechanism of docetaxel action is not fully understood, docetaxel is known to act as a microtubule-targeting agent that disrupts the dynamic process of microtubule assembly and disassembly, leading to cell cycle arrest and apoptosis (27). Some of the differentially expressed genes identified as modulated by docetaxel are related to cytoskeleton and spindle organization (RUVBL1) and cell to stroma adhesion (SPARC) that are important survival mechanisms associated with drug sensitivity $(28,29)$.

The SPARC gene (secreted protein acid rich in cysteine; also termed osteonectin) encodes a matricellular protein that acts in various biological processes, including embryonic development, tissue remodeling, angiogenesis, proliferation, differentiation and cell migration and invasion (30). Altered expression of SPARC has been demonstrated in different types of tumors, however the role played by SPARC in cancer physiopathology is not fully understood and remains controversial $(31,32)$.

In breast cancer patients, SPARC overexpression has been associated with a poor prognosis $(33,34)$. Besides its role in ECM production, SPARC is also able to bind to many ECM components and growth factors to modulate their activity (30). Thus SPARC appears to not have a direct structural role, but instead acts as an important mediator of cell-matrix interaction and cell function, influencing the cell microenvironment and possibly drug availability $(35,36)$. HB4a cells that are more sensitive to docetaxel exposure showed high expression levels of SPARC, which was down-regulated by intensive treatment with docetaxel. On the other hand, SPARC down-regulation was observed in both C5.2 and SKBR3 cells that express high levels of ERBB2, indicating that SPARC down-regulation could be associated with ERBB2 overexpression. However, the down-regulation of SPARC transcripts observed in C5.2 compared to HB4a cells could not be attributed solely to $E R B B 2$ overexpression, as it was not affected by $E R B B 2$ siRNA knockdown.

Tai et al (37) showed that low expression levels of SPARC are associated with decreased sensitivity to chemotherapy, and that restoration of SPARC expression, both in vivo and in vitro, is capable of reversing the resistant phenotype of colorectal cancer cells. These authors provided evidence that SPARC expression increases the sensitivity of colorectal cancer cells to radiation and 5-FU (Fluorouracil) due to modulation of the tumor microenvironment by SPARC, leading to increased apoptosis and blood vessel formation (37). Recent studies, demonstrated that the SPARC gene promoter is hypermethylated in colorectal tumors and that colorectal cells exposed to 5-aza-2'-desoxicytidine show increased expression of SPARC and higher sensitivity to 5-FU (38). These data suggest that SPARC could be a potential candidate marker for sensitivity to different chemotherapeutic drugs including docetaxel.

The RUVBL1 gene (also known as TIP49/Pontin52) localized on chromosome 3q21 encodes an ATP-dependent DNA helicase that shows homology to rat TIP49, a $49 \mathrm{kDa}$ TATA box-binding interacting protein (39). RUVBL1 acts as an important co-factor of oncogenic transformation mediated 
by c-myc $(40)$ and $B$-catenin $(41,42)$. In the present study, we found down-regulation of RUVBL1 transcripts in C5.2 cells that overexpress the ERBB2 oncogene compared to HB4a cells, but this expression pattern was not reversed by siRNAmediated ERBB2 knockdown. However, RUVBL1 expression was modulated by docetaxel treatment and generated a similar expression pattern in both cell lines after docetaxel exposure, suggesting that RUVBL1 expression could be associated with docetaxel sensitivity and resistance.

Gartner et al (43) showed that RUVBL1 associates with tubulin and has an agonist effect on in vitro tubulin assembly, and RUVBL1-tubulin co-localize to the centrosomes. Fielding et al (44) showed that RUVBL1 is required for the centrosomal localization of ILK (integrin liked kinase), one of the regulators of integrin mediated cell adhesion and cytoskeletal dynamics (45). In addition, Gartner et al (43) also showed that the extent of tubulin polymerization induced by the taxane paclitaxel is markedly increased in the presence of RUVBL1. Collectively, these results provide evidence that RUVBL1 could play a role in the sensitivity of cancer cells to anti-microtubule agents such as docetaxel and paclitaxel.

Although SPARC and RUVBL1 were found to be downregulated in the mammary cell lines overexpressing ERBB2, our siRNA results showed that SPARC and RUVBL1 are not solely regulated by $E R B B 2$ overexpression. On the other hand, our siRNA experiments helped to identify some genes that are either modulated (CENP-H) or not (ATAD4) by docetaxel treatment, and that are transcriptionally regulated by ERBB2 overexpression. The ATAD4 gene encodes a member of the ATPase family - AAA containing proteins, however its biological function is still unknown. In the present study, in corroboration with a previous study using cDNA microarray analysis (46) we found the ATAD4 gene transcripts to be up-regulated in C5.2 cells by SAGE and qPCR analysis. In addition, we demonstrated that the ATAD4 transcripts were significantly down-regulated after siRNA-mediated $E R B B 2$ knockdown, indicating that ATAD4 is transcriptionally regulated by $E R B B 2$ overexpression and could be associated with $E R B B 2$ transformation. Further experimental and clinical studies will be required to better evaluate the role played by ATAD4 in breast cancer development and progression.

The CENP-H gene, located on chromosome 5q15.2, encodes a member of the centromere and kinetochore protein family that plays a fundamental role in centromere assembly and sister chromatid segregation $(47,48)$. Chromosome missegregation is one of the main causes of aneuploidy, which is implicated in the tumorigenic process (49). CENP-H colocalizes with other members of the centromere and kinetochore protein family, such as CENP-A, CENP-B and CENP-C $(47,50)$. Knockdown of CENP-H in a chicken cell line demonstrated that CENP-H is a necessary component for kinetochore complex formation (51). In human cells, RNAi knockdown of CENP-H results in severe multipolar spindles and misaligned chromosomes that, after a few cell cycles, lead to cell death (52). Increased CENP-H expression has been shown to play a role in the tumorigenic process of colorectal, oral squamous cell and nasopharyngeal carcinomas (53-55). To date, no study has reported the role of CENP-H in breast tumors. We first detected up-regulation of CENP-H transcripts in C5.2 cells by SAGE analysis, but qPCR results subsequently showed that CENP-H transcripts are down-regulated in C5.2 and SKBR3 cell lines that overexpress ERBB2. However, as opposed to the ATAD4 gene, CENP-H transcripts were modulated by docetaxel treatment in both HB4a and C5.2 cells. Future studies will determine if altered expression of CENP-H also occurs in breast tumors and if this may have a predictive value for the docetaxel response.

The SAGE method allowed us to identify a large number of transcripts implicated in different cellular pathways that were up- or down-regulated by docetaxel in human mammary cell lines expressing different levels of the oncogenic protein erbB2. Whether these changes in expression are causally related to the transformation of the mammary cell lines by $E R B B 2$ and/or implicated with chemotherapeutic resistance warrants future investigation in additional experimental and clinical studies. Further in vitro and in vivo studies are needed to elucidate the biological role of these genes and the possible association with sensitivity or resistance to docetaxel.

\section{Acknowledgements}

We would like to thank Daniel Guariz Pinheiro and Anemari R. Dinarte for their assistance with the bioinformatics tools. We would also like to thank Simone A. de Bessa Garcia and Sibeli Salaorni for technical assistance. This work was supported by FAPESP - Fundação de Amparo a Pesquisa do Estado de São Paulo (grant nos. 02/01524-9 and 06/01026-0). This work was also supported in part by CNPq (304949/ 2006-0).

\section{References}

1. Jemal A, Siegel R, Ward E, Hao Y, Xu J, Murray T and Thun MJ: Cancer statistics. CA Cancer J Clin 57: 43-66, 2008.

2. Lønning PE: Study of suboptimum treatment response: lessons from breast cancer. Lancet Oncol 4: 177-185, 2003.

3. Pasquier E and Kavallaris M: Microtubules: a dynamic target in cancer therapy. IUBMB Life 60: 165-170, 2008.

4. Noguchi S: Predictive factors for response to docetaxel in human breast cancers. Cancer Sci 97: 813-820, 2006.

5. Gelmon K: The taxoids: paclitaxel and docetaxel. Lancet 344 : 1267-1272, 1994.

6. Herbst RS and Khuri FR: Mode of action of docetaxel - a basis for combination with novel anticancer agents. Cancer Treat Rev 29: 407-415, 2003.

7. Hamilton A and Hortobagyi G: Chemotherapy: what progress in the last 5 years? J Clin Oncol 23: 1760-1775, 2005.

8. Fulton B and Spencer CM: Docetaxel: a review of its pharmacodynamic and pharmacokinetic properties and therapeutic efficacy in the management of metastatic breast cancer. Drugs 51: 1075-1092, 1996.

9. McDonald SL, Stevenson DA, Moir SE, Hutcheon AW, Haites NE, Heys SD and Schofield AC: Genomic changes identified by comparative genomic hybridisation in docetaxel-resistant breast cancer cell lines. Eur J Cancer 41: 1086-1094, 2005.

10. Shalli K, Brown I, Heys SD and Schofield AC: Alterations of beta-tubulin isotypes in breast cancer cells resistant to docetaxel. FASEB J 19: 1299-1301, 2005.

11. Brown I, Shalli K, McDonald SL Moir SE, Hutcheon AW, Heys SD and Schofield AC: Reduced expression of p27 is a novel mechanism of docetaxel resistance in breast cancer cells. Breast Cancer Res 6: R601-R607, 2004.

12. Myioshi Y, Taguchi T, Kim SJ, Tamaki Y and Noguchi S: Prediction of response to docetaxel by immunohistochemical analysis of CYP3A4 expression in human breast cancer. Breast Cancer 12: 11-15, 2005.

13. Egawa C, Miyoshi Y, Takamura Y, Taguchi T, Tamaki Y and Noguchi S: Decreased expression of BRCA2 mRNA predicts favorable response to docetaxel in breast cancer. Int $\mathbf{J}$ Cancer 95: 255-259, 2001. 
14. Ooe A, Kato K and Nogushi S: Possible involvement of CCT5 RGS3 and YKT6 genes up-regulated in p53-mutated tumors in resistance to docetaxel in human breast cancers. Breast Cancer Res Treat 101: 305-315, 2007.

15. Yu D, Liu B, Jing T, et al: Overexpression of both p $185 \mathrm{c}-$ erbB2 and $170 \mathrm{mdr}-1$ renders breast cancer cells highly resistant to taxol. Oncogene 16: 2087-2094, 1998.

16. Ciardiello F, Caputo R, Pomatico G, De Laurentiis M, De Placido S, Bianco AR and Tortora G: Resistance to taxanes is induced by c-erbB-2 overexpression in human MCF$10 \mathrm{~A}$ mammary epithelial cells and is blocked by combined treatment with an antisense oligonucleotide targeting type protein kinase A. Int J Cancer 85: 710-715, 2000.

17. Slamon DJ, Clark GM, Wong SG, Levin WJ, Ullrich A and McGuire WL: Human breast cancer: correlation of relapse and survival with amplification of the HER-2/neu oncogene. Science 235: 177-182, 1987

18. Nagai MA, Marques LA, Torloni $\mathrm{H}$ and Brentani MM: Genetic alterations in c-erbB-2 protooncogene as prognostic markers in human primary breast tumors. Oncology 50: 412-417, 1993.

19. Azambuja E, Durbecq V, Rosa DD, Colozza M, Larsimont D, Piccart-Gebhart $\mathrm{M}$ and Cardoso F: HER-2 overexpression/ amplification and its interaction with taxane-based therapy in breast cancer. Ann Oncol 19: 223-232, 2008.

20. Nabholtz JM and Gligorov J: Docetaxel/trastuzumab combination therapy for the treatment of breast cancer. Expert Opin Pharmacother 6: 1555-1564, 2005.

21. Harris RA, Eichholtz TJ, Hiles ID, Page MJ and O'Hare MJ: New model of ErbB-2 over-expression in human mammary luminal epithelial cells. Int J Cancer 80: 477-484, 1999

22. Chomczynsk P and Sacchi N: Single-step method of RNA isolation by acid guanidinium thiocyanate-phenol-chloroform extraction. Anal Biochem 162: 156-159, 1987

23. Velculescu VE, Zhang L, Vogelstein B and Kinzler KW: Serial analysis of gene expression. Science 270: 484-487, 1995

24. dos Santos ML, Palanch CG, Salaorni S, Da Silva WA Jr and Nagai MA: Transcriptome characterization of human mammary cell lines expressing different levels of ERBB2 by serial analysis of gene expression. Int J Oncol 28: 1441-1461, 2006.

25. Hernández-Vargas H, Palacios J and Moreno-Bueno G: Molecular profiling of docetaxel cytotoxicity in breast cancer cells: uncoupling of aberrant mitosis and apoptosis. Oncogene 26: 2902-2913, 2007.

26. Fitzpatrick FA and Wheeler R: The immunopharmacology of paclitaxel (Taxol), docetaxel (Taxotere), and related agents. Int Immunopharmacol 3: 1699-1714, 2003.

27. Hernández-Vargas H, Palacios J and Moreno-Bueno G: Telling cells how to die: docetaxel therapy in cancer cell lines. Cell Cycle 6: 780-783, 2007.

28. Chrenek MA, Wong P and Weaver VM: Tumour-stromal interactions. Integrins and cell adhesions as modulators of mammary cell survival and transformation. Breast Cancer Res 3: 224-229, 2001.

29. Morin PJ: Drug resistance and the microenvironment: nature and nurture. Drug Resist Updat 6: 169-172, 2003.

30. Phan E, Ahluwalia A and Tarnawski AS: Role of SPARC matricellular protein in pathophysiology and tissue injury healing. Implications for gastritis and gastric ulcers. Med Sci Monit 13: RA25-RA30, 2007.

31. Fukunaga-Kalabis $\mathbf{M}$ and Herlyn $\mathbf{M}$ : Unraveling mysteries of the multifunctional protein SPARC. J Invest Dermatol 127: 2497-2498, 2007.

32. Podhajcer OL, Benedetti L, Girotti MR, Prada F, Salvatierra E and Llera AS: The role of the matricellular protein SPARC in the dynamic interaction between the tumor and the host. Cancer Metastasis Rev 27: 523-537, 2008.

33. Jones C, Mackay A and Grigoriadis A, et al: Expression profiling of purified normal human luminal and myoepithelial breast cells: identification of novel prognostic markers for breast cancer. Cancer Res 64: 3037-3045, 2004.

34. Watkins G, Douglas-Jones A, Bryce R, Mansel RE and Jiang WG: Increased levels of SPARC (osteonectin) in human breast cancer tissues and its association with clinical outcomes. Prostaglandins Leukot Essent Fatty Acids 72: 267-272, 2005.
35. Netti PA, Berk DA, Swartz MA, Grodzinsky AJ and Jain RK: Role of extracellular matrix assembly in interstitial transport in solid tumors. Cancer Res 260: 2497-2503, 2000.

36. Sung SY, Hsieh CL, Wu D, Chung LW and Johnstone PA: Tumor microenvironment promotes cancer progression, metastasis, and therapeutic resistance. Curr Probl Cancer 31: 36-100, 2007.

37. Tai IT, Dai M, Owen DA and Chen LB: Genome-wide expression analysis of therapy-resistant tumors reveals SPARC as a novel target for cancer therapy. J Clin Invest 115: 1492-1502, 2005.

38. Cheetham S, Tang MJ, Mesak F, Kennecke H, Owen D and Tai IT: SPARC promoter hypermethylation in colorectal cancers can be reversed by 5-Aza-2'deoxycytidine to increase SPARC expression and improve therapy response. Br J Cancer 98: 1810-1819, 2008.

39. Makino $\mathrm{Y}$, Kanemaki $\mathrm{M}$ and Koga $\mathrm{A}$, et al: Chromosome mapping and expression of human tip49 family genes. DNA Seq 11: 145-148, 2000.

40. Wood MA, McMahon SB and Cole MD: An ATPase/helicase complex is an essential cofactor for oncogenic transformation by c-Myc. Mol Cell 5: 321-330, 2000.

41. Bauer A, Huber O and Kemler R: Pontin52, an interaction partner of beta-catenin, binds to the TATA box binding protein. Proc Natl Acad Sci USA 95: 14787-14792, 1998.

42. Feng Y, Lee N and Fearon ER: TIP49 regulates beta-cateninmediated neoplastic transformation and $\mathrm{T}$-cell factor target gene induction via effects on chromatin remodeling. Cancer Res 63: 8726-8734, 2003

43. Gartner W, Rossbacher J, Zierhut B, et al: The ATP-dependent helicase RUVBL1/TIP49a associates with tubulin during mitosis. Cell Motil Cytoskeleton 56: 79-93, 2003.

44. Fielding AB, Dobreva I, McDonald PC, Foster LJ and Dedhar S: Integrin-linked kinase localizes to the centrosome and regulates mitotic spindle organization. J Cell Biol 180: 681-689, 2008.

45. Legate KR, Montañez E, Kudlacek O and Fässler R: ILK, PINCH and parvin: the tIPP of integrin signalling. Nat Rev Mol Cell Biol 7: 20-31, 2006.

46. Mackay A, Jones C, Dexter T, et al: cDNA microarray analysis of genes associated with ERBB2 (HER2/neu) overexpression in human mammary luminal epithelial cells. Oncogene 22: 2680-2688, 2003

47. Sugata N, Li S, Earnshaw WC, et al: Human CENP-H multimers colocalize with CENP-A and CENP-C at active centromere kinetochore complexes. Hum Mol Genet 9: 2919-2926, 2000.

48. Hemmerich P, Weidtkamp-Peters S, Hoischen C, Schmiedeberg L, Erliandri I and Diekmann S: Dynamics of inner kinetochore assembly and maintenance in living cells. J Cell Biol 180: 1101-1114, 2008.

49. Cimini D and Degrassi F: Aneuploidy: a matter of bad connections. Trends Cell Biol 15: 442-451, 2005.

50. Amor DJ, Kalitsis P, Sumer H and Choo KH: Building the centromere: from foundation proteins to $3 \mathrm{D}$ organization. Trends Cell Biol 14: 359-368, 2004.

51. Fukagawa T, Mikami Y, Nishihashi A, et al: CENP-H, a constitutive centromere component, is required for centromere targeting of CENP-C in vertebrate cells. EMBO J 20: 4603-4617, 2001 .

52. Orthaus S, Ohndorf S and Diekmann S: RNAi knockdown of human kinetochore protein CENP-H. Biochem Biophys Res Commun 348: 36-46, 2006.

53. Tomonaga T, Matsushita K, Ishibashi M, et al: Centromere protein $\mathrm{H}$ is up-regulated in primary human colorectal cancer and its overexpression induces aneuploidy. Cancer Res 65: 4683-4689, 2005

54. Liao WT, Song LB, Zhang HZ, et al: Centromere protein $\mathrm{H}$ is a novel prognostic marker for nasopharyngeal carcinoma progression and overall patient survival. Clin Cancer Res 13: 508-514, 2007.

55. Shigeishi H, Higashikawa $\mathrm{K}$, Ono $\mathrm{S}$, et al: Increased expression of CENP-H gene in human oral squamous cell carcinomas harboring high-proliferative activity. Oncol Rep 16: 1071-1075, 2006. 